\title{
Type of Renal Scintigraphy
}

\section{Hawraa Alsabea*}

Almana Group Hospital, Saudi Arabia

\begin{abstract}
Renal scan is used to diagnose certain kidney diseases. It shows not only the anatomy of the kidneys, also the function as well by using specific radionuclide. The functional information allows doctors to give early diagnose of certain diseases and various medical conditions much sooner than other imaging examinations. This study aimed to know how well people know about kidney nuclear imaging. A survey was conducted for 64 participants and it covered a variety of questions. The study showed that the highest percentage of knowledge about nuclear medicine was within the student group, 70-60\%. The physician's percentages were closed or even slightly lower than the percentages of others group.
\end{abstract}

Keywords: Renal scan; Kidney diseases; Radionuclide imaging; Single-photon emission computed tomography; Cortical imaging

\section{Introduction}

Since the early 1950s, it has been possible to measure renal function with radiopharmaceuticals. Techniques have evolved from urine counting and crude probe detectors to measurements of plasma clearance, dynamic functional imaging, and Single Photon Emission Computed Tomography (SPECT), cortical imaging. In recent years, some indications previously reserved for renal scintigraphy have been shifted to ultrasound, Computed Tomography (CT), or Magnetic Resonance imaging (MRI). However, the ability to image and quantify function can provide information not available by anatomical imaging methods. Nuclear medicine techniques still provide the best problem-solving tools in many clinical situations. Indications for renal scintigraphy include differentiating between obstructive from non-obstructive hydronephrosis, assessing the significance of renal artery stenosis, searching for postoperative leaks, and the evaluation of infection. Quantifying differential function and assessing viability is useful in the evaluation of complications that can occur after surgery or trauma. The ability to quantify function by effective renal plasma flow (ERPF) and glomerular filtration rate (GFR) can provide a better measurement of function than estimations based on serum creatinine. This can be done by using many radiopharmaceuticals that have been developed to assess different aspects of renal function based on binding characteristics and clearance pathways [1].

\section{Objective}

1. The aim of this study was to provide the types of renal scintigraphy.

2. To differentiate between the $\mathrm{Tc}^{99 \mathrm{~m}} \mathrm{MAG} 3$ and $\mathrm{Tc}^{99 \mathrm{~m}} \mathrm{DTPA}$.

3. Assess people's knowledge about nuclear medicine renal scintigraphy.

\section{Literature Review}

Renal scan is used to diagnose certain types of kidney diseases. It shows not only the anatomy of the kidneys, but the function as well by using specific radiotracer. The functional information allows radionuclide imaging to diagnose various medical conditions much sooner than other imaging examinations. The urinary system consists of two kidneys, ureters, bladder and urethra. The kidneys are reddish, bean shaped organs located on the posterior abdominal wall, one on each side of the vertebral column, behind the peritoneum and below the diaphragm. The right kidney is slightly lower than the left. The kidney is composed of thin outer area which is the cortex, and thick inner area which is the medulla. The nephron is the functional unit of the kidney which located in the renal cortex. It consists of a glomerulus and a renal tubule. There are three functions of the nephron including filtration of blood plasma by the glomeruli, reabsorption by the tubules of materials from the glomerular filtrate required in the body, and secretion of certain materials by the tubules. Overall, the main function of the kidneys include regulating the composition of the blood and remove wastes from the blood in the form of urine, balancing water and electrolytes, helping in regulating blood pressure by secreting Renin enzyme, and last, contributing to metabolism by synthesizing new glucose and participating in synthesis of vitamin D (Figure 1) [2].

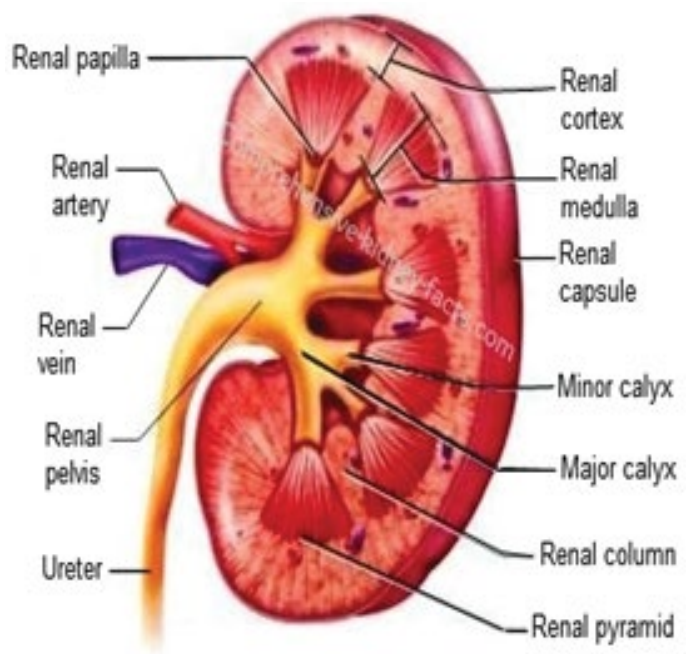

Figure 1: Anatomy of the kidney.

*Corresponding author: Hawraa Alsabea, Almana Group Hospitals, Saudi Arabia Tel: 0547527887; E-mail: hawraa.j.alsabea@hotmail.com

Received November 02, 2017; Accepted November 08, 2017; Published November 20, 2017

Citation: Alsabea H (2017) Type of Renal Scintigraphy. J Nucl Med Radiat Ther 8 : 347. doi: 10.4172/2155-9619.1000347

Copyright: (c) 2017 Alsabea H. This is an open-access article distributed under the terms of the Creative Commons Attribution License, which permits unrestricted use, distribution, and reproduction in any medium, provided the original author and source are credited. 


\section{Radiopharmaceuticals}

\section{Tc $^{99 m}$ DTPA (diethylenetraimine pent acetic acid)}

It is a physiology inert compound that diffuses rapidly into the extra-vascular space following intravenous injection. Its molecular characteristics are such that is cleared from the plasma purely by glomerular filtration. Dynamic imaging $\mathrm{Tc}^{99 \mathrm{~m}} \mathrm{DTPA}$ reveals rapid transit through the renal cortex with activity appearing in the collection system within a few minutes. It reaches a peak at 3-4 minutes after injection. It is a good agent for demonstrating lesions with the kidneys because of its rapid clearance, and finally it demonstrates obstruction of the collecting system [3].

\section{Tc ${ }^{99 m}$ MAG3 (mercaptoacetyltriglycine)}

It is essentially the same as $\mathrm{OIH}$, the clearance is only $50-60 \%$. The effective renal plasma flow, ERPF, cannot be directly measured by using $\mathrm{Tc}^{99 \mathrm{~m}} \mathrm{MAG} 3$, so a correction factor, based on correlation with $\mathrm{OIH}$ clearance need to be used. The extraction efficiency is 2-3 times higher that $\mathrm{Tc}^{99 \mathrm{~m}} \mathrm{DTPA}$ but is lower than I123-HIO. Tc ${ }^{99 \mathrm{~m}}$ MAG3 currently represents the best compromise for routine dynamic imaging. It is a simple $\mathrm{Tc}^{99 \mathrm{~m}} \mathrm{kit}$, so can be made up at any time for an urgent procedure. The advantage of using $\mathrm{Tc}^{99 \mathrm{~m}} \mathrm{MAG} 3$ over $\mathrm{Tc}^{99 \mathrm{~m}} \mathrm{DTPA}$ becomes more apparent as renal function deteriorates.

The features of this radiotracer include the excellent imaging properties and lower total body radiation and also it is excreted by tubular secretion [3].

\section{Tc ${ }^{99 m}$ DMSA (2-3 dimercaptosuccinic acid or succimer)}

$\mathrm{Tc}^{99 \mathrm{~m}} \mathrm{DMSA}$ is avidly taken up by cells the proximal tubule with $35 \%$ of the injection activity being localized in the renal cortex by one hour. Renal uptake continues to rise, leveling off at about 6 hours post-injection, by which time about $50 \%$ of the injection dose can be accounted for. The remainder is cleared by other organs, primarily liver and spleen, but skeletal clearance is also a factor in infants. Tc ${ }^{99 m} \mathrm{DMSA}$ is subject to degradation due to oxidation and, if uncontrolled, will result in reduced renal uptake, increased background activity, and high liver uptake. For this reason, the radiopharmaceutical should be injected as soon as possible after reconstitution within $\mathrm{Tc}^{99 \mathrm{~m}}$ pertechnetate [3].

\section{Difference between $\mathrm{Tc}^{99 \mathrm{~m}} \mathrm{DTPA}$ and $\mathrm{Tc}^{99 \mathrm{~m}} \mathrm{MAG}_{3}$}

$\mathrm{Tc}^{99 \mathrm{~m}} \mathrm{DTPA}$ was first introduced into clinical use in 1970 and since then has remained one of the agents of choice for diagnosing urinary tract obstruction. $\mathrm{Tc}^{99 \mathrm{~m}} \mathrm{DTPA}$ is relatively small molecule which can pass through the endothelial membrane. Following intravenous injection $\mathrm{Tc}^{99 \mathrm{~m}} \mathrm{DTPA}$ rapidly diffuses through the extracellular fluid. The renal clearance from the body is done by glomerular filtration with $96 \%$ of the injected dose being cleared in the first 24 hrs. Due to the small amount of plasma protein binding and tubular secretion which occurs, glomerular filtration rate is underestimated by approximately $8 \%$ and must be accounted for when measuring absolute GFR. Peak renal activity is reached after 3 minutes when $5 \%$ of the injected activity is present in each kidney. There is little or no secretion of $\mathrm{Tc}^{99 \mathrm{~m}} \mathrm{DTPA}$ by the renal tubules.

Tc ${ }^{99 m}$ MAG3 was developed in the 1980's as an alternative for 1131 Iodine ortho-iodohippurate $(\mathrm{OIH})$. Which had poor imaging properties, could not be used for renal perfusion imaging and also had a high radiation dose per imaginable photon. Following intravenous injection, $\mathrm{Tc}^{99 \mathrm{~m}}$ Mertiatide, $\mathrm{Tc}^{99 \mathrm{~m}} \mathrm{MAG3}$ is rapidly excreted by the kidneys. Active tubular secretion accounts for approximately $89 \%$ of the excretion of the administered dose with the remaining $11 \%$ of the dose excreted via glomerular filtration. With normal renal function $70 \%$ of the administered dose is excreted within 30 minutes of injection and over $95 \%$ after 3 hours peak renal activity is seen within 3 minutes of injection. Tc ${ }^{99 \mathrm{~m}}$ MAG3 has a high first pass extraction efficiency which is three times greater activity is less than with $\mathrm{Tc}^{99 \mathrm{~m}} \mathrm{DTPA}$ (Table 1) [2].

\section{Types of Renal Scintigraphy}

There are different types of renal scintigraphy imaging; renal function and perfusion scan (Dynamic renal scan), Captopril scan, Cortical renal scan $\left(\mathrm{Tc}^{99 \mathrm{~m}} \mathrm{DMSA}\right)[4,5]$. The main indication for renal function and perfusion scan (Dynamic renal) scan are analyzing renal function and perfusion, determining glomerular filtration rate (GFR), evaluate for renal obstruction, evaluate renal transplant kidney, and finally evaluate renal reflux [5].

Patient preparation includes hydrating the patient for 30-60 min prior to the study. Patient must void before scanning. The adult dose of $\mathrm{Tc}^{99 \mathrm{~m}} \mathrm{DTPA}$ is $5-10 \mathrm{mCi}$ and $2.5-5 \mathrm{mCi}$ of $\mathrm{Tc}^{99 \mathrm{~m}} \mathrm{MAG}$. For pediatric, dose can be weight adjusted to age adjusted, it varies according to departmental protocol. The injection must be administrated as a bolus intravenous injection without flushing the syringe [3].

Camera acquisition and technique includes position the camera under the table for POST images, $128 \times 128$ matrixes for Tc ${ }^{99 m}$ MAG3. After injecting the radiopharmaceutical as a bolus, begin acquisition at the same time. Acquire dynamic flow study using 5 second frames, for 12 frames (60 seconds in total). Acquire dynamic function/excretion phase of the study using 15 seconds per frames for 112 frames (28 minutes in total). Acquire static image of injection site for 60 seconds to ensure complete injection. Get the patient up and have them empty their bladder completely. Then acquire a static post-void image of the kidneys for 60 seconds. Images must be seen by nuclear medicine physician for any additional delayed views (Figure 2) [3].

Urinary tract obstruction is a common problem seen a lot by urologists. Urinary tract obstruction can occur at any point in the urinary tract, starting from the kidneys to the urethral meatus. It can develop tumors, strictures, anatomical abnormalities, or functional

\begin{tabular}{|l|l|l|}
\hline Variables & Tc99m-DTPA & Tc99m-MAG-3 \\
\hline Excretion & Filtration 90\% extracted from blood by 4 hours & Tubular excretion (95\%) and filtration (5\%) \\
\hline Renal function estimate & $\begin{array}{l}\text { GFR May underestimate, since some TC99M-DTPA is bound to } \\
\text { plasma proteins }\end{array}$ & ERPF \\
\hline Response to captopril in RAS & $\begin{array}{l}\text { Decreased activity } \\
\text { (since GFR goes down) }\end{array}$ & $\begin{array}{l}\text { Increased activity (since GFR and hence tubular secretion } \\
\text { goes down) }\end{array}$ \\
\hline Parenchyma visualization & $\begin{array}{l}\text { Poor due to short reprographic phase. Even worse in patients with } \\
\text { obstruction or renal impairment, since filtration is impaired }\end{array}$ & Good \\
\hline Dose-limiting organ & Bladder & Bladder \\
\hline Dose & $370-740 \mathrm{MBq}(10-20 \mathrm{mCi})$ & $370-740 \mathrm{MBq}(10-20 \mathrm{mCi})$ \\
\hline
\end{tabular}

Table 1: Differences between the two radiopharmaceuticals in excretion, response to captopril in ras, parenchyma visualization dose-limiting organ, and patient dose. 
abnormalities. Obstructiveaeropathy can result in pain, urinary tract infection, loss in renal function, or possibly sepsis or death (Figure 3) [6].

Diuretic radionuclide renography easily detects whether a partial or total obstruction is present in Figure 4. Figure 5 shows the normal results of no obstruction presence and Figure 6 shows positive renogram for obstructive kidney function.

Renal transplantation is another procedure that can be done in

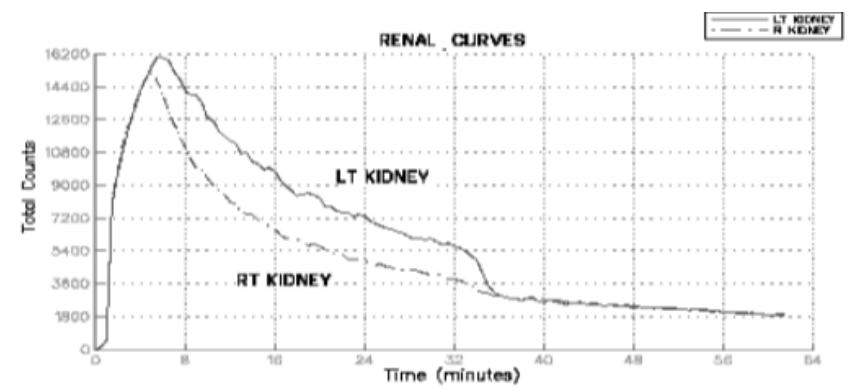

Figure 2: Time activity curve.

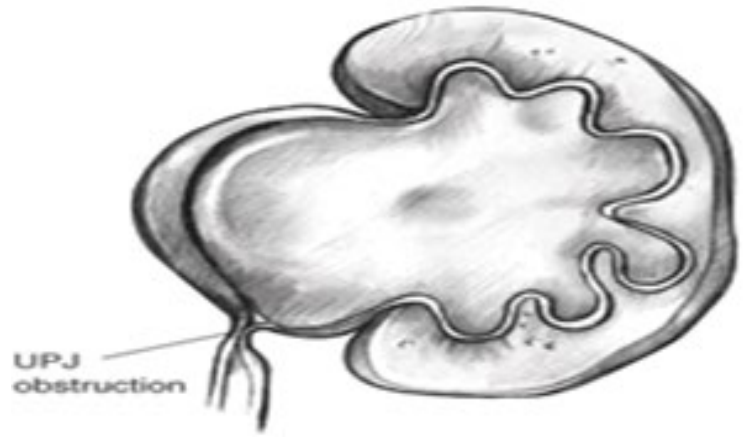

Figure 3: UPJ Obstruction

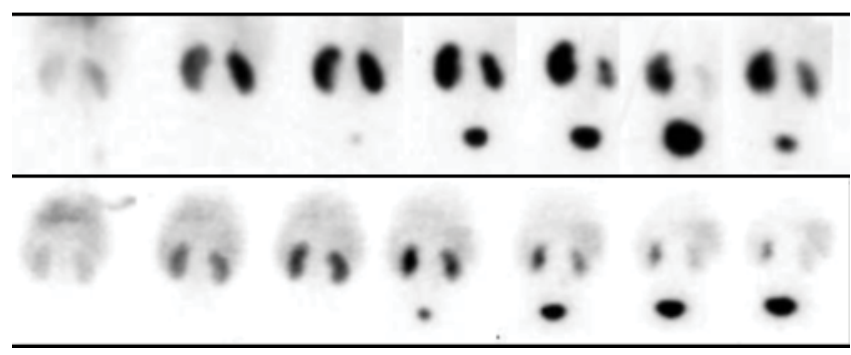

Figure 4: Diuretic renogram.

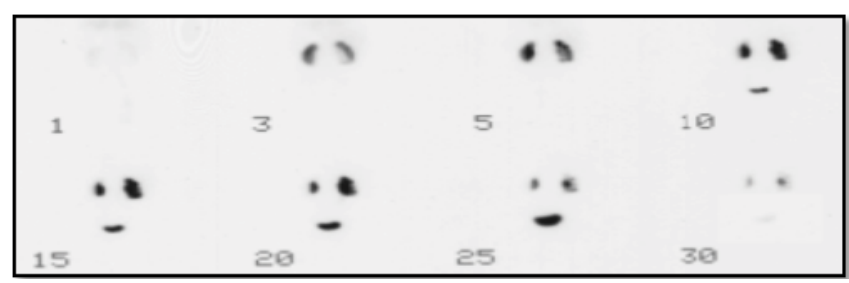

Figure 5: No obstruction.

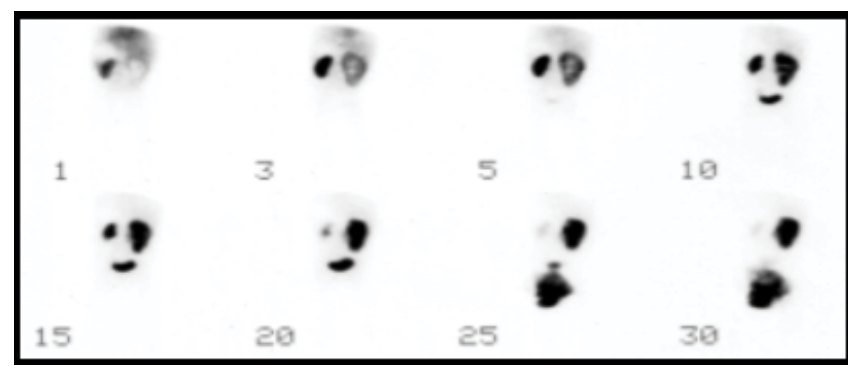

Figure 6: Obstructive.

nuclear medicine department using the radiopharmaceutical I131 Orthoiodohippurate (OIH), which was used in 1990s. In January of 1991, I131 OIH was replaced by $\mathrm{Tc}^{99 \mathrm{~m}} \mathrm{MAG}_{3}$. An empirical correction was used to convert $\mathrm{MAG}_{3}$ clearance to ERPF, otherwise the protocol remained essentially unchanged.

The rationale for the routine quantitative baseline study is to provide a reference point to determine whether function is improving or deteriorating in the immediate post-transplantation period. In 1995 the newer agent $\mathrm{Tc}^{99 \mathrm{~m}} \mathrm{MAG} 3$ was used [7]. The medical complication of this scan is to evaluate for mainly rejection and differentiate between acute and chronic rejection, or Acute tubular necrosis.

Acute rejection occurs in early 5 to 7 days or within first 3 months through cell mediated immunologic process. Patient who received the transplanted kidney may experience symptoms like fever, transplant enlargement with tenderness. After performing the scan, the findings may include enlarged kidney with poor perfusion, decrease GFR and ERPF, abnormal decrease of perfusion index, and Ga67 or $\mathrm{Tc}^{99 \mathrm{~m}}$ sulpher colloid accumulation in acute rejection. In chronic rejection, the rejection occurs within months or year with marked decrease in renal function. After performing the scan, the findings may include small kidney with poor perfusion, decrease uptake and excretion, decrease GFR or ERPF.

Last but not least, acute tubular necrosis. The scan finding may represents normal perfusion but minimal uptake with flat Reno gram curve [8]. Figure 7 shows the evaluation of renal transplant.

Renal captopril scintigraphy is a diagnosis of RVH. When a severe narrowing of the renal artery causes a reduction in renal blood flow which cannot be compensated by the auto regulation system, the glomerular filtration pressure falls. Thus, the kidney secrets an enzyme called Renin that, in turn, acts on plasma protein called angiotensinogen to form angiotensinogen. Angiotensinogen converting enzyme (ACE) then acts on angiotensinogen I to produce angiotensinogen II which is a potent vasoconstrictor at arteriolar level. Captopril also called (ACE inhibitor), blocks the conversion of angiotensin I to angiotensin II $[9,10]$.

The indications for this scan are renal artery stenosis (RAS), ischemic nephropathy, and Reno vascular hypertension (RVH). Patient preparation includes discontinue diuretic therapy 1-3 days prior to the study, discontinue the ACEI therapy as per following: 1 day: Captopril and 3 days for any other ACE inhibitors. The patient must be well hydration. Because patient hydration is very important in this study, the patient must drink the water orally but if the patient is not able to consume the water orally, intravenous hydration can be done. The BP 


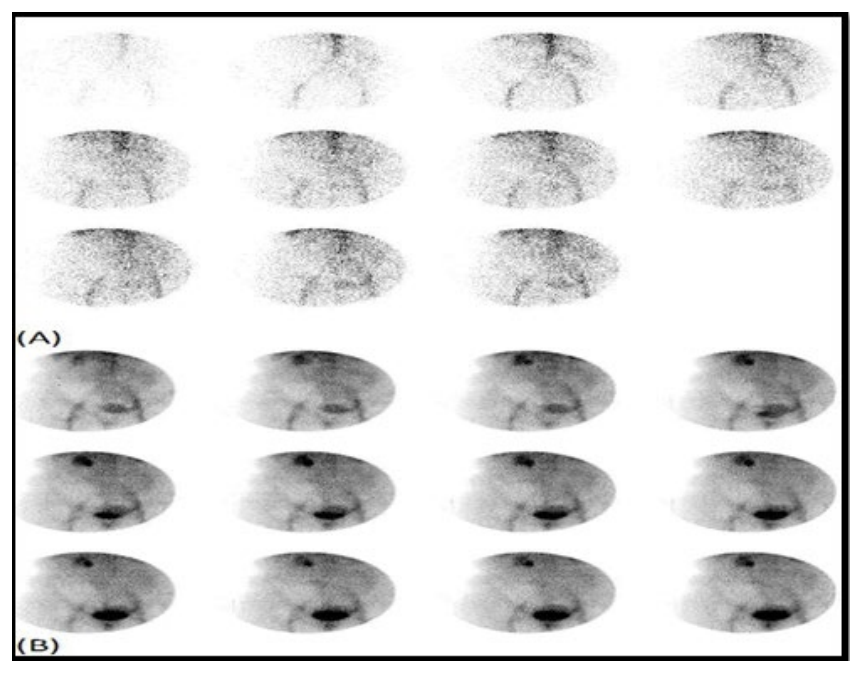

Figure 7: Renal transplant.

and pulses reading must be recorded every $10 \mathrm{~min}$. The patient must empty the bladder immediately before the scan. Captopril injection (25-50 $\mathrm{mg}$ ) is given at $1 \mathrm{hr}$ pre-scan.

The injected radiopharmaceutical is $\mathrm{Tc}^{99 \mathrm{~m} M A G 3}$ and it is administrated via bolus IV injection without flushing the syringe. In the first day of the scan, it is called the baseline scan and 1-2 mCi of $\mathrm{TC}^{99 \mathrm{~m}} \mathrm{MAG} 3$ injected into the patient followed by post-Capto scan (8$10 \mathrm{mCi}$ ). On the 2 days test, baseline scan is performed with $8-10 \mathrm{mCi}$ on day 1 and Post-Capto scan $(8-10 \mathrm{mCi})$ on day 2 . This test has to be performed using a gamma camera with large field of view collimator, energy window around $140 \mathrm{KeV}$, and $20 \%$ window around $140 \mathrm{KeV}$. Patient position is the same as native kidneys flow and Perfusion scan [3].

Renovascular hypertension is high blood pressure due to narrowing of the arteries that carry blood to the kidneys. This condition is also called renal artery stenosis. The most common cause of renal artery stenosis is a blockage in the arteries due to high cholesterol. This problem occurs when a sticky, fatty substance called plaque builds up on the inner lining of the arteries. When the arteries that carry blood to your kidneys become narrow, less blood flows to the kidneys. The kidneys mistakenly respond as if your blood pressure is low. As a result, they release hormones that tell the body to hold on to more salt and water. This causes your blood pressure to rise [11]. Figure 8 shows how the body reacts during renovascular hypertension.

The indications for renal cortical scintigraphy are hydronephrosis, pyelonephritis, cyst, tumors, and congenital anomalies. Patient preparation include well hydration and emptying the bladder immediately before the scan. The used radiopharmaceutical $\mathrm{Tc}^{99 \mathrm{~m}} \mathrm{DMSA}$ $5 \mathrm{mCi}$, given to the patient through IV cannulation. Camera acquisitions include using a gamma camera with either LEAP or Pinhole collimator, energy window is $140 \mathrm{KeV}$ and $20 \%$ window.

Acute pyelonephritis (APN), is a common infectious disease during childhood, it often leads to renal scarring. Acute pyelonephritis results from bacterial invasion of the renal parenchyma. Bacteria usually reach the kidney by ascending from the lower urinary tract. Bacteria may also reach the kidney via the bloodstream. Timely diagnosis and management of acute pyelonephritis has a significant impact on patient outcomes. It may result in irreversible renal scarring, which itself can

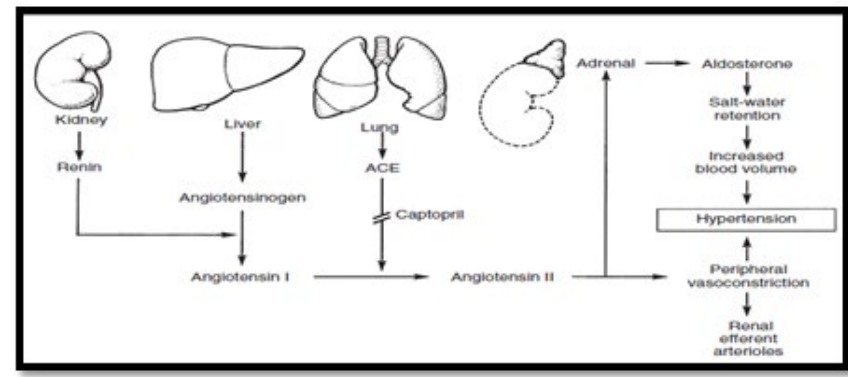

Figure 8: Renovascular hypertension.

lead to long-term complications. Renal scarring as a complication of APN has been estimated to occur in up to $64 \%$ of pediatric kidneys. Cortical renal scintigraphy with $\mathrm{T}^{99 \mathrm{~m}} \mathrm{DMSA}$ was shown to be highly sensitive and specific for the detection and localization of acute inflammatory changes in APN (Figure 9) [12].

Congenital anatomic anomalies of the GU tract are more common than those of any other organ system. Urinary tract anomalies predispose patients to many complications, including infection, obstruction, stasis, calculus formation, and impaired renal function. Genital anomalies may cause voiding or sexual dysfunction, impaired fertility, psychosocial difficulties, or a combination. GU anomalies frequently require surgical reconstruction. Many GU anomalies are diagnosed in utero via routine prenatal ultrasonography. Some congenital renal anomalies (eg, autosomal dominant polycystic kidney disease and modularly cystic disease, hereditary nephritis typically do not manifest until adulthood (Figure 10) [13].

Kidney cysts are round pouches of fluid that form on or in the kidneys. They can be associated with serious disorders that may impair kidney function. Simply, kidney cysts are noncancerous cysts that rarely cause complications. It is not clear what causes simple kidney cysts. Typically, only one cyst occurs on the surface of a kidney, but multiple cysts can affect one or both kidneys. However, simple kidney cysts aren't the same as the cysts that form with polycystic kidney disease. Simple kidney cysts are often detected during an imaging test performed for another condition. Simple kidney cysts that do not cause signs or symptoms usually do not require treatment (Figure 11) [14].

\section{Methodology}

In this study, we aimed to know how well people know about renal scan. A survey was conducted for 64 participants. It covered a variety of questions. The participants were from different groups of people such as doctors from different specialties (21), college students (23) and regular people (20)

\section{Results}

Figure 12 describes the number of people they returned answer by the questions. Table 2 shows results of general people who took the survey, Table 3 shows results of students who took the survey and Table 4 shows results of physician who took the survey.

1. We wanted to know the knowledge of participants about renal imaging in nuclear medicine. We found that the highest percentage of knowledge was within the group of college students and it was about $70 \%$ followed by $57 \%$ which was for physicians (Figure 13) 


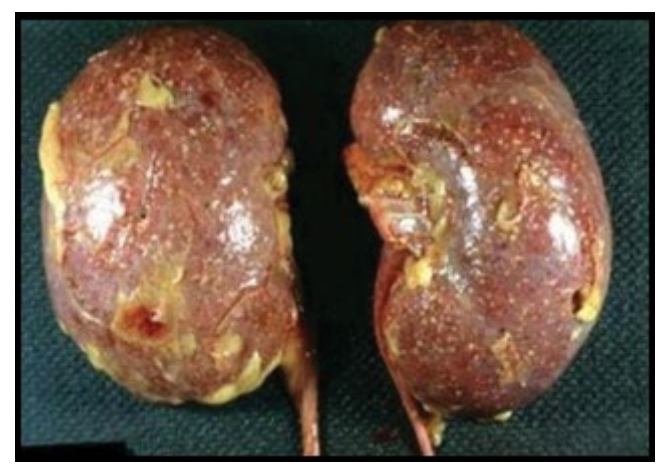

Figure 9: Acute pyelonephritis.

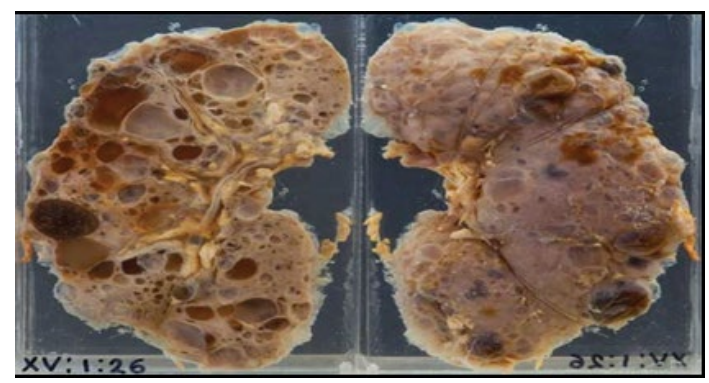

Figure 10: Congenital anomalies.

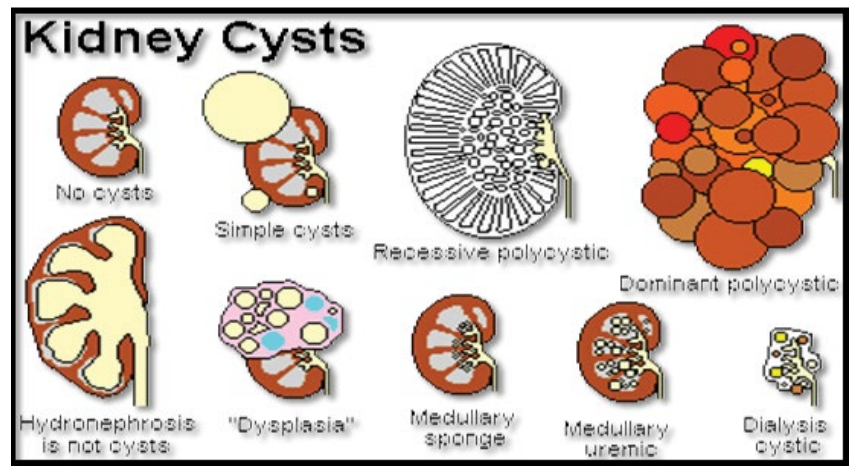

Figure 11: Cysts.

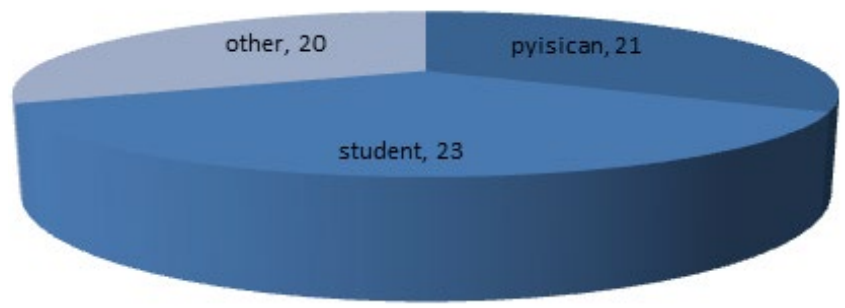

Figure 12: Survey results.

2. We asked participants whether the patients after having nuclear imaging can set and contact with other patients. The highest percentage was $65 \%$ for the other group who think that patents after nuclear imaging can set with other patients, whereas only $49 \%$ of physicians answered yes (Figure 14).

3. When we asked participants whether pregnant women with renal cancer can have nuclear imaging, $61 \%$ of students said no and 52.4 of the physicians answered with no (Figure 15).

4. We asked participants whether on the day of nuclear imaging the patients must be fasting. We found that $70 \%$ of group others think that patients must be fasting on the day of imaging (Figure 16).

5. Participants were asked if they can think of any complications or side effects that can happen to the patient after the injection. About $61 \%$ of the students said yes followed by $50 \%$ of group others and only $43 \%$ of physicians said yes (Figure 17 ).

\begin{tabular}{|c|c|c|c|c|c|c|}
\hline \multirow{2}{*}{ S.No } & \multicolumn{4}{|c|}{ Physician } & \multicolumn{3}{c|}{ Physician } \\
\cline { 2 - 7 } & Yes & No & Neutral & Yes & No & Neutral \\
\hline Q1 & 12 & 4 & 5 & $57.10 \%$ & $19.00 \%$ & $23.80 \%$ \\
\hline Q2 & 9 & 8 & 4 & $42.90 \%$ & $38.10 \%$ & $19.00 \%$ \\
\hline Q3 & 8 & 11 & 3 & $38.10 \%$ & $52.40 \%$ & $14.30 \%$ \\
\hline Q4 & 9 & 6 & 6 & $42.90 \%$ & $28.60 \%$ & $28.60 \%$ \\
\hline Q5 & 9 & 6 & 6 & $42.90 \%$ & $28.60 \%$ & $28.60 \%$ \\
\hline Q6 & 16 & 3 & 2 & $76.20 \%$ & $14.30 \%$ & $9.50 \%$ \\
\hline Q7 & 16 & 4 & 1 & $76.20 \%$ & $19.00 \%$ & $4.80 \%$ \\
\hline Q8 & 9 & 8 & 4 & $42.90 \%$ & $38.10 \%$ & $19.00 \%$ \\
\hline Q9 & 8 & 10 & 3 & $38.10 \%$ & $47.60 \%$ & $14.30 \%$ \\
\hline Q10 & 15 & 4 & 2 & $71.40 \%$ & $19.00 \%$ & $9.50 \%$ \\
\hline Q11 & 12 & 8 & 1 & $57.10 \%$ & $38.10 \%$ & $4.80 \%$ \\
\hline
\end{tabular}

Table 2: Results of physician who took the survey.

\begin{tabular}{|c|c|c|c|c|c|c|}
\hline \multirow{2}{*}{ S.No } & \multicolumn{3}{|c|}{ Student } & \multicolumn{3}{c|}{ Student } \\
\cline { 2 - 7 } & yes & No & Neutral & yes & No & Neutral \\
\hline Q1 & 16 & 7 & 0 & $69.60 \%$ & $30.40 \%$ & $0.00 \%$ \\
\hline Q2 & 10 & 8 & 5 & $43.50 \%$ & $34.80 \%$ & $21.70 \%$ \\
\hline Q3 & 8 & 14 & 1 & $34.80 \%$ & $60.90 \%$ & $4.30 \%$ \\
\hline Q4 & 9 & 7 & 7 & $39.10 \%$ & $30.40 \%$ & $30.40 \%$ \\
\hline Q5 & 14 & 1 & 8 & $60.90 \%$ & $4.30 \%$ & $34.80 \%$ \\
\hline Q6 & 12 & 7 & 4 & $52.20 \%$ & $30.40 \%$ & $17.40 \%$ \\
\hline Q7 & 17 & 2 & 4 & $73.90 \%$ & $8.70 \%$ & $17.40 \%$ \\
\hline Q8 & 15 & 6 & 2 & $65.20 \%$ & $26.10 \%$ & $8.70 \%$ \\
\hline Q9 & 8 & 15 & 0 & $34.80 \%$ & $65.20 \%$ & $0.00 \%$ \\
\hline Q10 & 17 & 5 & 1 & $73.90 \%$ & $21.70 \%$ & $4.30 \%$ \\
\hline Q11 & 14 & 5 & 4 & $60.90 \%$ & $21.70 \%$ & $17.40 \%$ \\
\hline
\end{tabular}

Table 3: Results of students who took the survey.

\begin{tabular}{|c|c|c|c|c|c|c|}
\hline \multirow{2}{*}{ S.No } & \multicolumn{4}{|c|}{ Other } & \multicolumn{3}{c|}{ Other } \\
\cline { 2 - 7 } & Yes & No & Neutral & Yes & No & Neutral \\
\hline Q1 & 10 & 10 & 0 & $50.00 \%$ & $50.00 \%$ & $0.00 \%$ \\
\hline Q2 & 13 & 3 & 4 & $65.00 \%$ & $15.00 \%$ & $20.00 \%$ \\
\hline Q3 & 5 & 8 & 7 & $25.00 \%$ & $40.00 \%$ & $35.00 \%$ \\
\hline Q4 & 14 & 2 & 4 & $70.00 \%$ & $10.00 \%$ & $20.00 \%$ \\
\hline Q5 & 10 & 6 & 4 & $50.00 \%$ & $30.00 \%$ & $20.00 \%$ \\
\hline Q6 & 11 & 5 & 4 & $55.00 \%$ & $25.00 \%$ & $20.00 \%$ \\
\hline Q7 & 11 & 4 & 5 & $55.00 \%$ & $20.00 \%$ & $25.00 \%$ \\
\hline Q8 & 12 & 5 & 3 & $60.00 \%$ & $25.00 \%$ & $15.00 \%$ \\
\hline Q9 & 2 & 17 & 1 & $10.00 \%$ & $85.00 \%$ & $5.00 \%$ \\
\hline Q10 & 14 & 1 & 5 & $70.00 \%$ & $5.00 \%$ & $25.00 \%$ \\
\hline Q11 & 11 & 2 & 7 & $55.00 \%$ & $10.00 \%$ & $35.00 \%$ \\
\hline
\end{tabular}

Table 4: Results of general people who took the survey. 


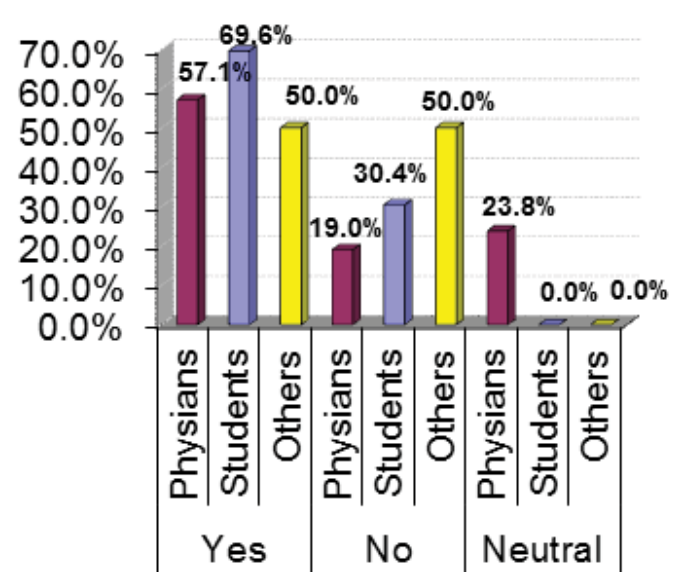

Figure 13: Participants about renal imaging in nuclear medicine.

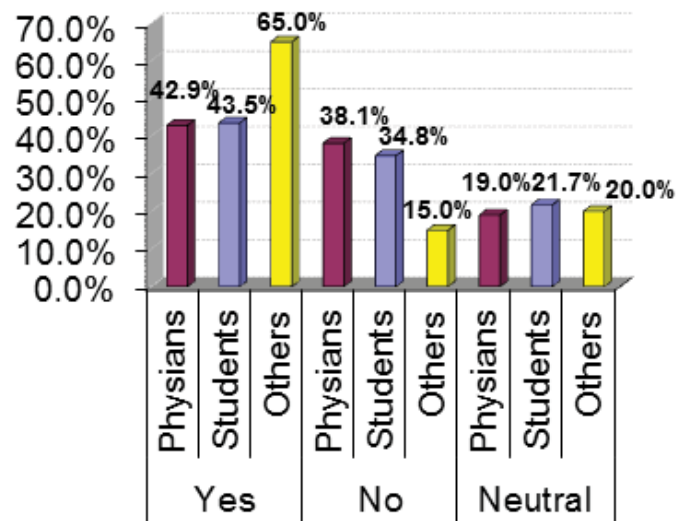

Figure 14: Participants about whether the patients after having nuclear imaging can set and contact with other patients.

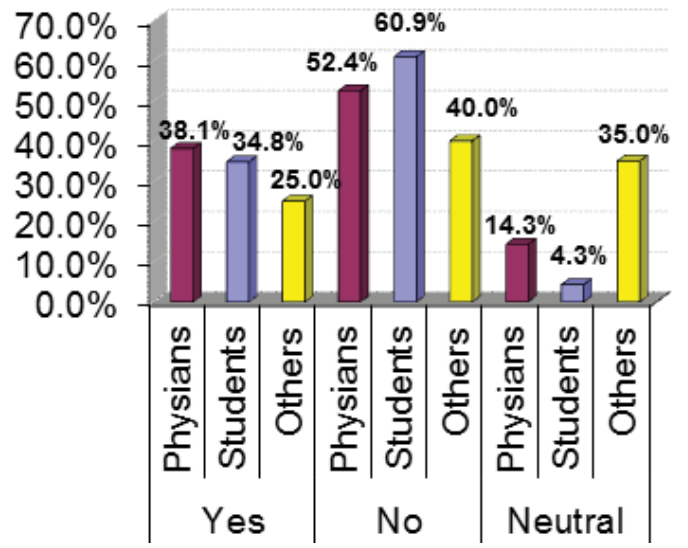

Figure 15: Participants about pregnant women with renal cancer can have nuclear imaging.

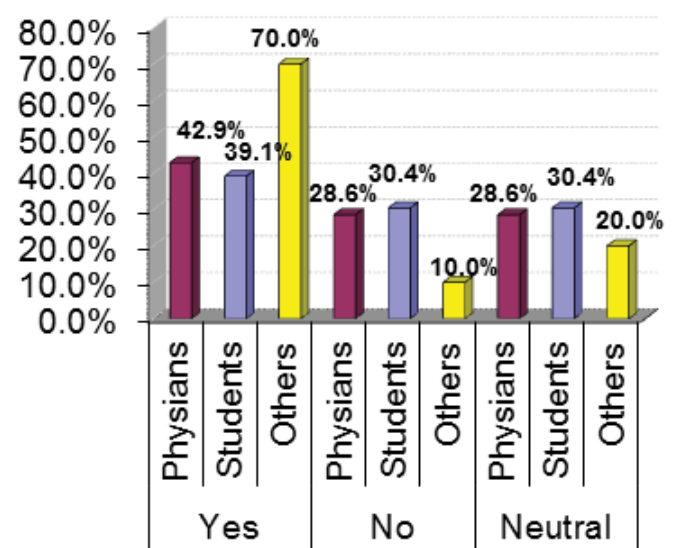

Figure 16: Participants about whether on the day of nuclear imaging the patients must be fasting.

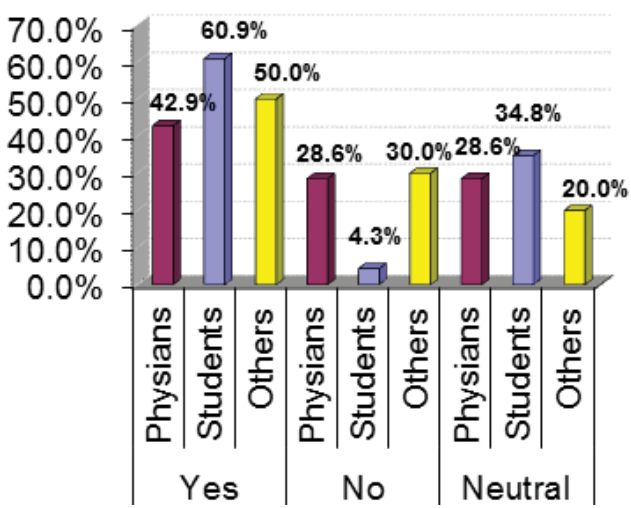

Figure 17: Participants about any complications or side effects that can happen to the patient after the injection.

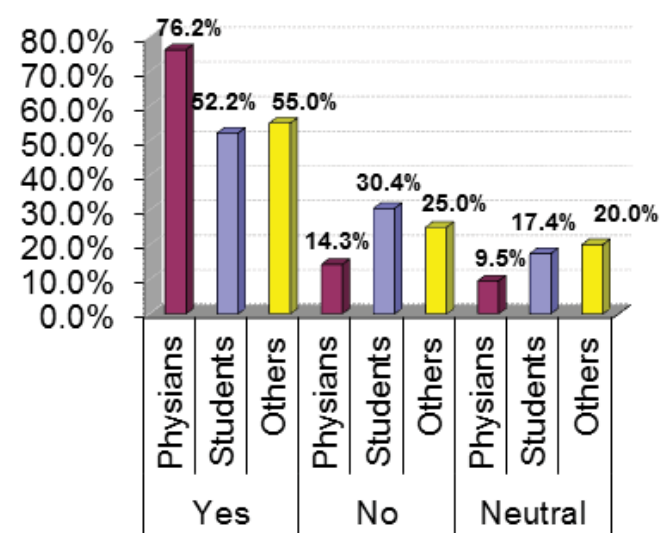

Figure 18: Participants about nuclear imaging danger for newborn.

6. Participants were asked if nuclear imaging dangerous for newborn. The highest percentage for answering yes was $76.2 \%$ for physicians followed by $55 \%$ and $52.2 \%$ for others and students respectively (Figure 18).

7. When participants were asked do you think that transplanted 
kidney can be examined by nuclear renal scan, physicians and students were got close percentages for answering yes that is $76.2 \%$ and $73.9 \%$ respectively (Figure 19 ).

8. We asked the participants whether nuclear renal scan can detect renal infection $65.2 \%$ of students said yes followed by $60 \%$ for group others whereas only $43 \%$ of physicians thinks it can (Figure 20).

9. Participants were asked whether they know anything about procedure imaging for renal scan and radiation protection. The majority of the participants among all the groups said they don't know. For example about $48 \%$ of physician said they don't know and $65.2 \%$ of the students answered with no (Figure 21).

10. When participants were asked do you think that urinary tract obstruction can be detected using nuclear renal scan, the answer was yes for about $70-74 \%$ of participants amongst the three groups (Figure 22).

11. Finally we asked the Participants whether they know if Reno vascular hypertension can be detected using nuclear renal scan. The highest percentages were for the answer yes and they were as following: $61 \%$ for students followed by $57 \%$ and $55 \%$ for physicians and group others, respectively (Figure 23).

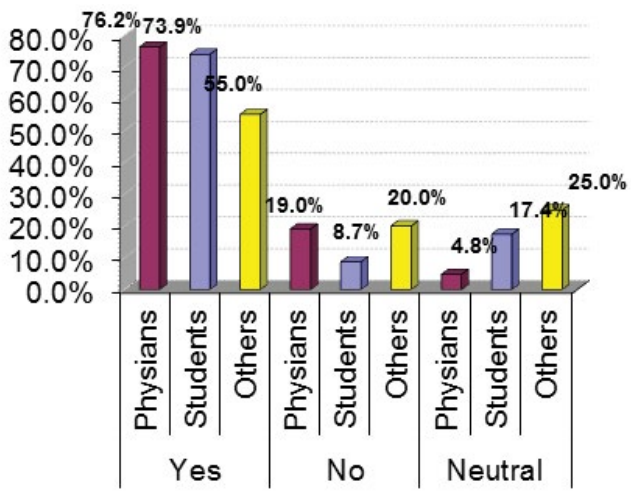

Figure 19: Participants about transplanted kidney can be examined by nuclear renal scan.

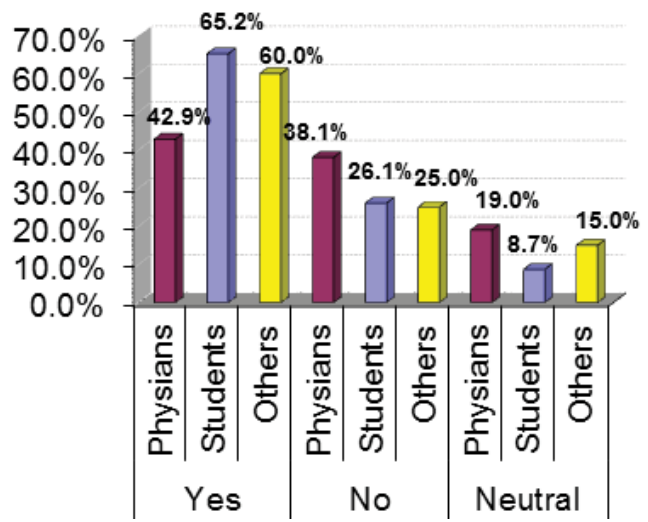

Figure 20: Participants about transplanted kidney can be examined by nuclear renal scan.

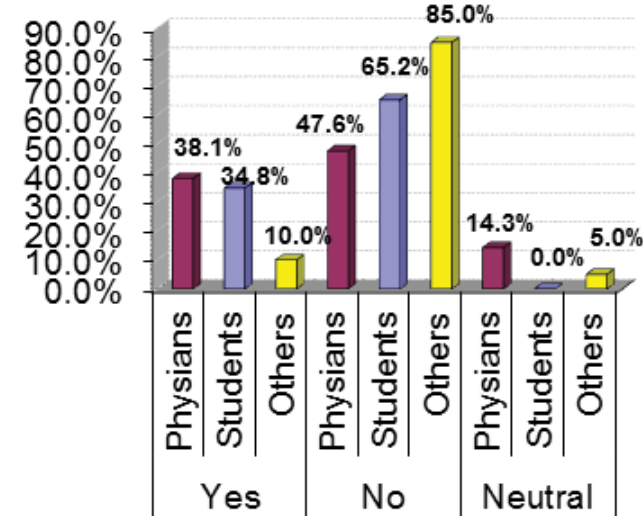

Figure 21: Participants about procedure imaging for renal scan and radiation protection.

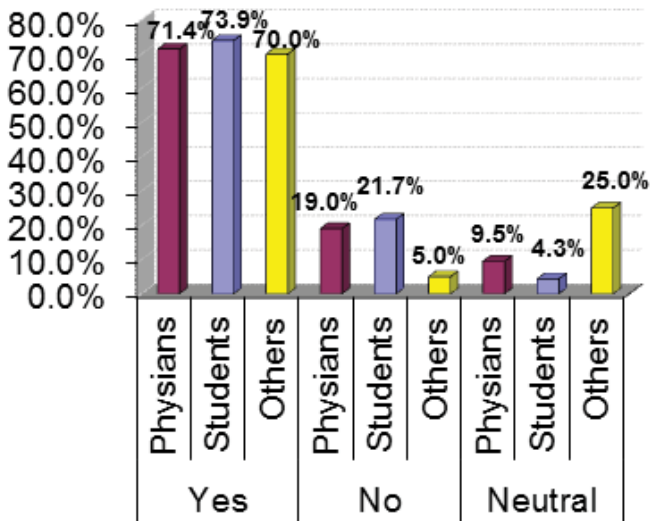

Figure 22: Participants about urinary tract obstruction can be detected using nuclear renal scan.

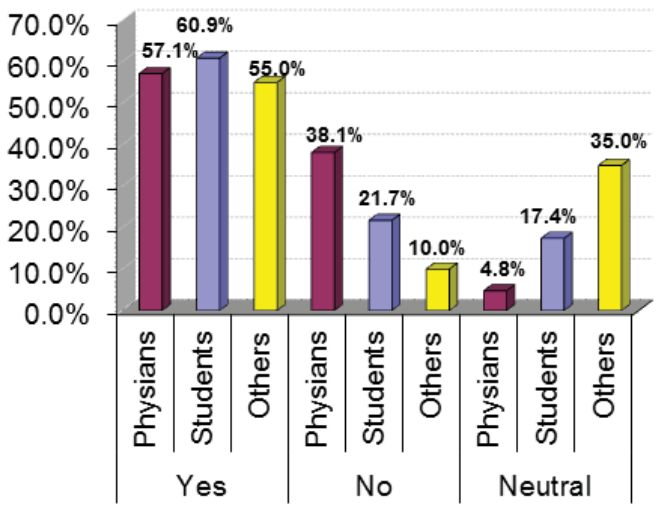

Figure 23: Participants about Reno vascular hypertension can be detected using nuclear renal scan.

\section{Discussion}

In this research paper we aimed to study how well people know about nuclear medication, its safety and its medical applications. We 
prepared a questionnaire that involves $11 \mathrm{Yes} / \mathrm{No} / \mathrm{Neutral}$ questions and we distributed it to the participants who were divided into three groups: physicians, students and others. Our study showed that the highest percentage of knowledge about nuclear medicine was within the student group. This is because they were nuclear medicine students. Their percentages ranged from $70-60 \%$. The results revealed that the students demonstrated the highest percentages for answering correctly 6 out of 11 questions. The questions are numbers $1,3,5,8,10$ and 11 .

Question 3 was a tricky one, because nuclear imaging is dangerous for pregnant women, but the question asked about pregnant women who are also with renal cancer. Although the majority of people in each group answered no, some of them chose to say yes because the pregnant woman is a cancer patient.

Our results also showed that nuclear medicine students know well about nuclear imaging applications (questions 8, 10 and 11) as they were superior in their percentages amongst the other participants. Unexpectedly, the percentages for physicians who answer accurately were fluctuated. The physician's percentages were closed or even slightly lower than the percentages of others group. It is because the physicians that were entered this survey were from specialists far away from nuclear medicine. Their specialists were dermatology, dentist, surgery, pharmacy, nursing, urologist and anesthesia. The evidence of their little knowledge about nuclear medicine showed clearly in the results of the questions $2,4,5,8$ and 11 . Interestingly, in question 4 where participants were asked whether patients must be fasting on the day of nuclear imaging, $70 \%$ of them say yes, based on their experience with other kinds of tests where patients must be fasting such as for lipid blood test and endoscopies.

\section{Conclusion}

This study demonstrated the scope of people knowledge about nuclear medicine. It showed that physicians from specialist's not involving nuclear medicine have little information about nuclear imaging. Furthermore, our results showed that general people (not student or physicians) have some information about nuclear imaging. We can suggest that conferences and workshops should be arranged within hospitals and universities to educate people and medical staff about nuclear medicine science and its procedures and applications.

\section{References}

1. Ziessman HA, O'Malley PJ, Thrall JH, Fahey FH (1995) Nuclear medicine the requisites $4^{\text {th }}$ edition $2: 5-173$.

2. Owunwanne A, Patel M, Sadek S (1995) Dynamic renal imaging in obstructive renal pathology. 1: 5-13.

3. Sharp PF, Gemmell GH, Murray AD (1996) (EDS) Practical Nuclear Medicine 11: 17-211.

4. Mettler FA, Guiberteau MJ (1983) Essentials of nuclear medicine. 9: 11-316.

5. Roca I. Diagnosis of Urinary Tract Obstruction.

6. Russell CD, Yang H, Gaston RD, Hudson SL, Diethelm AG, et al. (2000) Prediction of renal transplant survival from early postoperative radioisotope studies. J Nuc Med 41: 1332-1336.

7. Wing YH (2001) Medical complications after renal transplantation. 6: 1-4.

8. Hattner SH, Miller SW, Schimmel D (1975) Significance of renal asymmetry in bone scans. J Nuc Med 16: 161-163.

9. Sharp P, Gemmell HG, Murray AD, Philip SC (1996) Captopril Renography. Practical Nuc Med11: 222-223.

10. Fanti S, Dondi M, Corbelli C, Monetti N (1993) Diagnosis of renovascular hypertension with captopril renal scintigraphy in a patient with a solitary kidney. J Nuc Med 34: 1166-1168.

11. Benador D, Benador N, Slosman DO, Nussle D, Mermillod B, et al. (1994) Cortical scintigraphy in the evaluation of renal parenchymal changes in children with pyelonephritis. J Pediatr 124: 17-20.

12. Rushton HG, Majd M, Chandra R, Yim D (1998) Evaluation of 99mTcdimercaptosuccinic acid renal scans in experimental acute pyelonephritis in piglets. J Urol 140: 1169-1174.

13. Stamey T (1980) Pathogenesis and Treatment of Urinary Tract Infections. Baltimore, MD: Williams \& Wilkins: 239-241.

14. Bailey RR, Lynn KL, Robson RA, Smith AH, turner JG, et al. (1996) DMSA rena scans in adults with acute pyelonephritis. Clin Nephrol 46: 99-104. 